\title{
Gazania spp.: A New Host of Lettuce Mosaic Potyvirus, and a Potential Inoculum Source for Recent Lettuce Mosaic Outbreaks in the Salinas Valley of California
}

Francisco Murilo Zerbini, Department of Plant Pathology, University of California, Davis 95616; Steven T. Koike, University of California Cooperative Extension, Salinas 93901; and Robert L. Gilbertson, Department of Plant Pathology, University of California, Davis 95616

\begin{abstract}
Zerbini, F. M., Koike, S. T., and Gilbertson, R. L. 1997. Gazania spp.: A new host of lettuce mosaic potyvirus, and a potential inoculum source for recent lettuce mosaic outbreaks in the Salinas Valley of California. Plant Dis. 81:641-646.

Lettuce mosaic potyvirus (LMV) outbreaks in the Salinas Valley of California have increased in recent years despite a comprehensive lettuce mosaic management program. In a previous study, it was established that new serologically and/or genetically distinct LMV strains were not responsible for these outbreaks. Therefore, the role of alternate hosts was investigated. Here we provide evidence that the ornamental plant, Gazania spp., is an alternate host of LMV. A number of lines of evidence were used to establish that gazanias were infected by LMV, including indirect enzyme-linked immunosorbent assay, dot blot hybridization with an LMV coat protein (CP) probe, and sap- and aphid-transmission of LMV from gazania to lettuce and Nicotiana benthamiana. Additionally, an LMV CP fragment was amplified from an infected gazania plant by reverse transcription-polymerase chain reaction, and the nucleotide sequence of this fragment was 99\% identical to the CP sequence of an LMV isolate from the Salinas Valley. We further show that LMV-infected gazanias are widely distributed in the Salinas Valley, and are present near areas where LMV outbreaks have occurred. Field experiments demonstrated that LMV could be transmitted from infected gazania to lettuce. LMV-infected gazanias also were found in local nurseries, suggesting that infection of gazania with LMV had occurred prior to planting in the Salinas Valley (i.e., lettuce was not serving as the source of inoculum for infection of gazania in the Salinas Valley). These results establish that gazania is an alternate host of LMV, and suggest that gazanias may be a primary inoculum source for recent lettuce mosaic outbreaks in the Salinas Valley.
\end{abstract}

Lettuce mosaic, caused by lettuce mosaic potyvirus (LMV), is one of the most damaging viral diseases of lettuce (Lactuca sativa L.) in the Salinas Valley of California (3). Symptoms of LMV infection in lettuce include yellow mosaic, leaf distortion, stunted plant growth, and, in some cases, necrotic spots on leaves $(13,14)$. In iceberg lettuce, the type of lettuce most commonly produced in the Salinas Valley, plants infected by LMV at an early stage of growth will not form heads, rendering plants unmarketable. LMV can be seedborne in lettuce, and is transmitted by many species of aphids in a non-persistent manner (13). Losses of up to $100 \%$ can occur in fields established with LMVinfected seed and having high aphid populations $(3,8)$.

In the 1940s and 1950s, lettuce mosaic nearly destroyed the lettuce industry in the Salinas Valley (4). The implementation of an integrated disease management strategy,

Corresponding author: Robert L. Gilbertson

E-mail: rlgilbertson@ucdavis.edu

Accepted for publication 7 March 1997.

Publication no. D-1997-0407-05R

(C) 1997 The American Phytopathological Society which includes the planting of seed indexed as LMV-free, weed control, and, more recently, a lettuce-free period, has significantly reduced the incidence of LMV in the Salinas Valley (3). However, beginning in the mid 1980s, LMV outbreaks in the Salinas Valley increased (10). Furthermore, it was observed that these outbreaks were occurring in the same areas, which suggested that the outbreaks were not due to planting of non-indexed seed lots. Two hypotheses were proposed to explain the appearance of these outbreaks: (i) the emergence or introduction of a new LMV strain(s) not detected by the antiserum used in the seed indexing program; or (ii) the virus had become established in alternate hosts that were serving as primary inoculum sources for the outbreaks. In a previous study it was established that the LMV isolates associated with these outbreaks were not serologically or genetically distinct LMV strains (14). Therefore, the role of alternate hosts in the outbreaks was next investigated.

LMV has a relatively wide host range that includes many common weeds such as Picris echioides L. (bristly oxtongue), Malva parviflora L. (cheeseweed), and Cirsium vulgare (Savi) Ten. (bull thistle), and ornamental plants such as Tagetes erecta L. (African marigold) and Osteo- spermum fruticosum (L.) Norl. (freeway daisy) $(5,9,13)$. In the Salinas Valley, alternate hosts have generally been considered to be of minor importance in the epidemiology of lettuce mosaic $(3,4)$, although it was recognized that weed hosts of LMV can be responsible for localized outbreaks (16). This latter finding led to the inclusion of weed control as part of the Salinas Valley LMV management strategy. However, the role of ornamental plants as alternate hosts of LMV received less attention. Recently, LMV has been identified in the freeway daisy (Osteospermum fruticosum) in the Salinas Valley (9), and in lisianthus (Eustoma grandiflorum (Raf.) Shinn.) in Italy (7). Here we report that another ornamental plant, Gazania spp., is an alternate host of LMV in the Salinas Valley, and present evidence that this plant may be an inoculum source for the recent LMV outbreaks. A preliminary report on this work has been published (15).

\section{MATERIALS AND METHODS}

LMV surveys. Weed, ornamental, and lettuce plants were initially collected in the Salinas Valley in March and October 1992. These surveys were concentrated in areas (hot spots) known to have had recent LMV outbreaks. Selected plants, with or without symptoms of viral infection, were collected and tested for LMV infection by an indirect enzyme-linked immunosorbent assay (I-ELISA) (2), using a polyclonal LMV antiserum raised against a Salinas Valley isolate of LMV (14). Additional surveys were conducted in March and October 1993, and February 1994. Gazania plants showing symptoms of viral infection were collected from commercial nurseries in the Salinas Valley in 1992, 1993, and 1994. Beginning in 1993, samples also were tested for infection by cucumber mosaic cucumovirus (CMV) and turnip mosaic potyvirus (TuMV) by I-ELISA. The CMV antiserum was provided by R. N. Campbell (University of California, Davis), and the TuMV antiserum was from the ATCC (Rockville, MD)

Electron microscopy. The leaf-dip method was used to observe virions from selected plants. A drop of $1 \%$ potassium phosphotungstate $(\mathrm{pH} 7.0)$ was placed on top of a formvar-coated copper grid and a cut leaf was placed in contact with the drop. After $1 \mathrm{~min}$, the excess liquid was blotted from the grid with filter paper, and 
the grid was viewed with a Zeiss EM109 transmission electron microscope.

Sap transmission. Sap inoculation of lettuce, Chenopodium quinoa Willd., Nicotiana benthamiana Domin, and gazania was carried out as previously described (14), except that $0.1 \%$ sodium diethyldithiocarbamate (Na-Dieca) was added to the grinding buffer instead of sodium bisulfite, and the sap was centrifuged for $5 \mathrm{~min}$ at $10,000 \times g$ prior to inoculating plants. Two morphologically distinct types of gazanias were used in the experiments: one with glabrous, lobed leaves and white flowers, and the other with non-glabrous, smooth leaves and yellow flowers. Gazanias were obtained from commercial sources, and were first tested for the absence of LMV and CMV by I-ELISA prior to inoculation. Following inoculation, plants were maintained in a greenhouse for 4 weeks. Infection was then determined based on the appearance of symptoms and by testing each inoculated plant by IELISA.

Dot blot hybridizations. To prepare samples for dot blot hybridizations, $0.25 \mathrm{~g}$ of leaf tissue was ground in $1 \mathrm{ml}$ of sodium citrate buffer $(50 \mathrm{mM}, \mathrm{pH} 8.3)$ containing $1 \%$ polyvinylpyrrolidone. The extract was transferred to a microfuge tube and centri- fuged for $10 \mathrm{~min}$ at $10,000 \times \mathrm{g}$. The supernatant was diluted $1: 1$ in $12 \times$ SSC $(1 \times$ SSC is $0.15 \mathrm{M} \mathrm{NaCl}$ plus $0.015 \mathrm{M}$ sodium citrate) (11) containing 6\% formaldehyde. Ten microliters of the plant extract was spotted onto Nytran nylon membranes (Schleicher \& Schuell, Keene, NH) that had been pre-incubated for $10 \mathrm{~min}$ in $20 \times$ SSC and air dried at room temperature. Membranes were hybridized with an LMV coat protein $(\mathrm{CP})$ probe under high stringency conditions (1). Probes were labeled with $\left[\alpha^{3}{ }^{32} \mathrm{P}\right]-\mathrm{dCTP}$ by nick translation (BRL, Gaithersburg, MD).

RT-PCR. Reverse transcription-polymerase chain reaction (RT-PCR) was carried out with gazania samples that tested positive for LMV infection by I-ELISA. RNA was extracted according to Langeveld et al. (6), except that the final RNA concentration was $0.1 \mathrm{mg} / \mathrm{ml}$ instead of 1.0 $\mathrm{mg} / \mathrm{ml}$. The greater dilution was needed because of PCR inhibitors that were present in sap prepared from gazania leaf tissue. Approximately $0.5 \mathrm{mg}$ of RNA was used in the RT-PCR reaction as previously described, with oligonucleotide primers that direct the amplification of a 600-bp fragment of the LMV CP gene (14). PCRamplified DNA fragments were cloned with the TA cloning system (Invitrogen

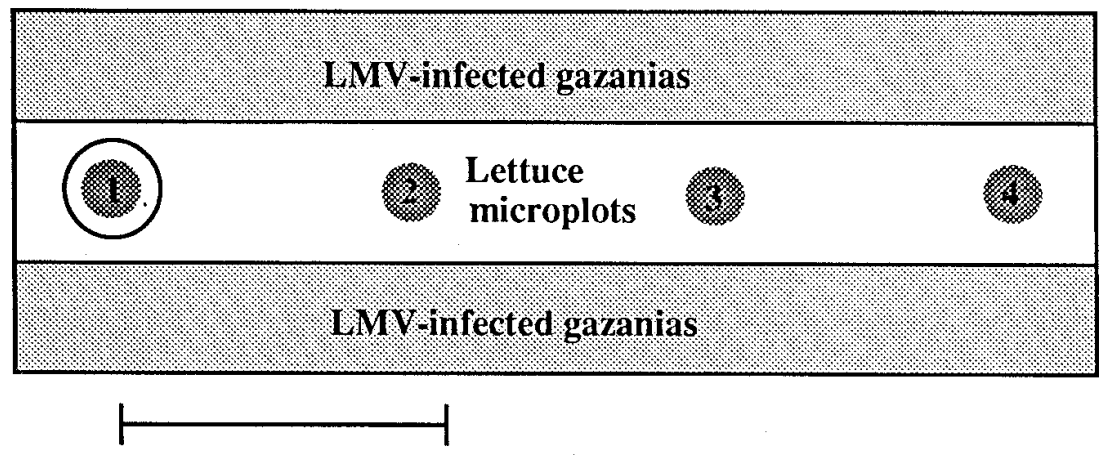

$30 \mathrm{~m}$

Fig. 1. Schematic representation of lettuce microplots established among gazania plantings in the Salinas Valley to evaluate transmission of lettuce mosaic potyvirus from gazania to lettuce. Four microplots (1 to 4), each with 10 lettuce transplants, were established at each location; a circular (shown for microplot 1) or rectangular buffer area of bare ground was established around the microplots at each location.
Corp., San Diego, CA), and sequenced by the dideoxynucleotide chain termination method (12) with Sequenase (USB, Cleveland, $\mathrm{OH})$, according to the manufacturer's instructions.

Aphid transmission. The green peach aphid (Myzus persicae Sulz.) was used as the vector in all experiments. Non-viruliferous aphids, raised on pepper (Capsicum annuum L.) plants, were starved for $1 \mathrm{~h}$ and then placed on leaves of LMV-infected source plants for a 2-min acquisition access period. Aphids were then transferred to uninfected plants. Plants were sprayed with insecticide $24 \mathrm{~h}$ later and kept in the greenhouse for 4 weeks. LMV infection of inoculated plants was determined by IELISA.

Field experiments. Field plots were established at four locations in the Salinas Valley in 1993, and five locations in 1994. At each location, four microplots, each having 10 lettuce transplants that were grown from seed indexed free of LMV infection, were established among plantings of gazania that had been previously determined to have LMV-infected plants based on I-ELISA assays (Fig. 1). The additional location in 1994 was a "control" that consisted of a planting of gazania that did not have LMV-infected plants (based on absence of viral symptoms and selected plants testing negative for LMV by IELISA). All of the locations were near commercial lettuce fields; the LMVinfected gazania plantings were within 4 to $67 \mathrm{~m}$ of commercial fields and the "control" planting was within $640 \mathrm{~m}$ of a commercial field. The distance between locations ranged from 1.6 to $7.1 \mathrm{~km}$. Four weeks after transplanting, the lettuce plants were harvested and tested for LMV infection by I-ELISA.

\section{RESULTS}

Incidence of LMV infection in Gazania spp. In the LMV host surveys conducted in March and October 1992, a total of 132 samples representing 16 plant species were collected from 18 locations throughout the Salinas Valley and tested for the presence of LMV by I-ELISA.

Table 1. Detection of lettuce mosaic potyvirus (LMV), turnip mosaic potyvirus (TuMV), and cucumber mosaic cucumovirus (CMV) in selected plants collected from the Salinas Valley ${ }^{\mathrm{a}}$

\begin{tabular}{|c|c|c|c|c|c|c|c|c|c|c|c|c|c|c|}
\hline \multirow[b]{3}{*}{ Plant species } & \multicolumn{14}{|c|}{ Date of survey } \\
\hline & \multicolumn{2}{|c|}{1992} & \multicolumn{4}{|c|}{ March 1993} & \multicolumn{4}{|c|}{ October 1993} & \multicolumn{4}{|c|}{ February 1994} \\
\hline & $\frac{\text { March }}{\text { LMV }}$ & $\begin{array}{c}\text { Oct. } \\
\text { LMV }\end{array}$ & $\begin{array}{l}\text { LMV } \\
\text { only }\end{array}$ & $\begin{array}{l}\text { CMV } \\
\text { only }\end{array}$ & $\underset{\mathrm{CMV}}{\mathrm{LMV}+}$ & TuMV & $\begin{array}{l}\text { LMV } \\
\text { only }\end{array}$ & $\begin{array}{l}\text { CMV } \\
\text { only }\end{array}$ & $\begin{array}{c}\text { LMV + } \\
\text { CMV }\end{array}$ & TuMV & $\begin{array}{l}\text { LMV } \\
\text { only }\end{array}$ & $\begin{array}{l}\text { CMV } \\
\text { only }\end{array}$ & $\begin{array}{c}\text { LMV + } \\
\text { CMV }\end{array}$ & TuMV \\
\hline Gazania spp. & $13 / 14^{\mathrm{b}}$ & $16 / 33$ & $20 / 63$ & $22 / 63$ & $12 / 63$ & $2 / 63$ & $39 / 67$ & $15 / 67$ & $8 / 67$ & $2 / 67$ & $7 / 21$ & $6 / 21$ & $5 / 21$ & $0 / 21$ \\
\hline Osteospermum sp. & $0 / 1$ & $2 / 5$ & $-^{\mathrm{c}}$ & - & - & - & $1 / 4$ & $0 / 4$ & $0 / 4$ & $0 / 4$ & - & - & - & - \\
\hline Lactuca sativa & $1 / 3$ & $16 / 32$ & $6 / 15$ & $0 / 15$ & $0 / 15$ & $2 / 15$ & $5 / 8$ & $1 / 8$ & $0 / 8$ & $3 / 8$ & $8 / 14$ & $0 / 14$ & $0 / 14$ & $2 / 14$ \\
\hline Cirsium vulgare & $1 / 1$ & - & - & - & - & - & - & - & - & - & - & - & - & - \\
\hline Picris echioides & $3 / 3$ & $5 / 6$ & - & - & - & - & - & - & - & - & - & - & - & - \\
\hline Lactuca serriola & $0 / 3$ & $1 / 2$ & - & - & - & - & - & - & - & - & - & - & - & - \\
\hline
\end{tabular}

${ }^{a}$ LMV, TuMV, and CMV were detected by indirect enzyme-linked immunosorbent assay.

${ }^{\mathrm{b}}$ Number of plants positive/total number sampled.

${ }^{\mathrm{c}}$ No plants of these species were collected. 
LMV was not detected in 10 plant species: Calangela sp., Chenopodium sp., cheeseweed (Malva parviflora), clover (Trifolium sp.), common groundsel (Senecio vulgaris L.), dandelion (Taraxacum officinale Wigg.), endive (Cichorium endivia L.), ice plant (Mesembryanthemum crystallinum L.), spiny sowthistle (Sonchus asper (L.) J. Hill), and turnip (Brassica napus L.). LMV was detected in six species: bristly oxtongue (Picris echioides), bull thistle (Cirsium vulgare), freeway daisy (Osteospermum fruticosum), gazania (Gazania spp.), prickly lettuce (Lactuca serriola L.), and lettuce (Lactuca sativa) (Table 1). Of these six species, all but Gazania spp. are known LMV hosts. Because of the high incidence of LMV infection in gazania plants collected in the March (93\% infection) and October surveys (49\% infection), additional surveys of gazania were conducted around LMV hot spots in the Salinas Valley in March and October 1993 and February 1994 (Table 1). Gazanias collected in the March and October 1993 surveys had a high incidence of LMV infection, 51 and $70 \%$ infection, respectively, as did gazanias collected in 1994 (57\% infection) (Table 1). Many of the gazania plants collected in these surveys showed symptoms of virus infection, including yellow mottling or mosaic, chlorotic spots, and leaf distortion (Fig. 2), and certain types of gazania showed more prominent symptoms than others (e.g., gazanias with nonglabrous leaves showed more prominent symptoms than those with glabrous leaves). However, there was not a consistent correlation between the presence of viruslike symptoms in gazania and LMV infection. For example, a number of gazania samples that tested positive for LMV infection by I-ELISA showed few or no symptoms, whereas other samples that showed symptoms tested negative, suggesting infection by another virus(es). Examination of leaf-dip preparations from gazanias showing symptoms of viral infection revealed different types of viruslike particles, including straight rods, bacilliform particles (rhabdovirus-like), isometric particles, and flexuous rods (presumably those of potyviruses) (data not shown). Based on these results and the subsequent sap transmission of CMV from gazania (see below), gazania samples were also tested for CMV and TuMV beginning in 1993. CMV was frequently detected in gazania and, in some cases, LMV and CMV were present in mixed infections (Table 1). TuMV was detected in only a few samples (Table 1).

Surveys of local nurseries were conducted in 1992, 1993, and 1994 to determine the incidence of LMV infection in commercially available gazanias. In all 3 years, gazanias showing symptoms of virus infection were found in all nurseries surveyed, and some of these plants were infected with LMV (Table 2). In 1992, LMV- infected gazanias were found in all five nurseries surveyed, with $64 \%$ of sampled plants infected. In 1993, LMV-infected gazanias were found in four of five nurseries surveyed, with $43 \%$ of sampled plants infected. In 1994, LMV-infected gazanias were found in only one of four nurseries surveyed, with $9 \%$ of sampled plants infected, despite striking, viruslike symptoms in most plants collected from these nurseries. CMV-infected gazanias were found in four of five nurseries in 1993

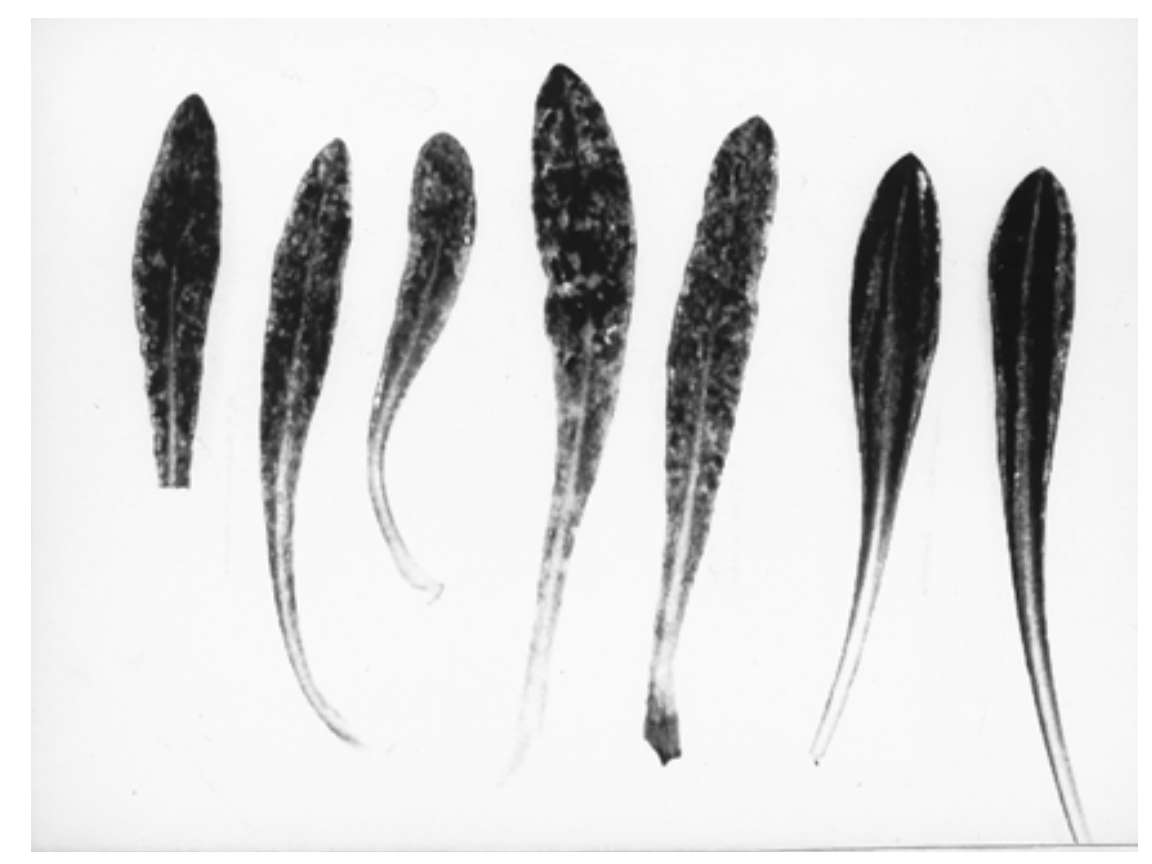

Fig. 2. Viruslike symptoms in the leaves of field-collected gazania plants.

Table 2. Detection of lettuce mosaic potyvirus (LMV) and cucumber mosaic cucumovirus (CMV) in gazanias showing symptoms of viral infection collected from commercial nurseries in the Salinas Valley $^{\mathrm{a}}$

\begin{tabular}{|c|c|c|c|c|c|c|c|}
\hline \multirow[b]{3}{*}{ Nursery } & \multicolumn{7}{|c|}{ Date collected } \\
\hline & \multirow[b]{2}{*}{$\begin{array}{c}1992 \\
\text { LMV }\end{array}$} & \multicolumn{3}{|c|}{1993} & \multicolumn{3}{|c|}{1994} \\
\hline & & $\begin{array}{c}\text { LMV } \\
\text { only }\end{array}$ & $\begin{array}{c}\text { CMV } \\
\text { only }\end{array}$ & $\underset{\text { CMV }}{\mathrm{LMV}+}$ & $\begin{array}{l}\text { LMV } \\
\text { only }\end{array}$ & $\begin{array}{c}\text { CMV } \\
\text { only }\end{array}$ & $\begin{array}{c}\text { LMV + } \\
\text { CMV }\end{array}$ \\
\hline$\# 1$ & $14 / 19^{b}$ & $1 / 10$ & $5 / 10$ & $3 / 10$ & $0 / 12$ & $5 / 12$ & $2 / 12$ \\
\hline \#2 & $4 / 8$ & $2 / 4$ & $1 / 4$ & $1 / 4$ & $0 / 5$ & $1 / 5$ & $0 / 5$ \\
\hline \#3 & $2 / 6$ & $0 / 5$ & $0 / 5$ & $0 / 5$ & $-^{\mathrm{c}}$ & - & - \\
\hline \#4 & $4 / 5$ & $4 / 5$ & $1 / 5$ & $0 / 5$ & $0 / 4$ & $2 / 4$ & $0 / 4$ \\
\hline$\# 5$ & $3 / 4$ & $0 / 4$ & $1 / 4$ & $1 / 4$ & $0 / 3$ & $0 / 3$ & $0 / 3$ \\
\hline
\end{tabular}

${ }^{a}$ LMV and CMV were detected by indirect enzyme-linked immunosorbent assay.

${ }^{\mathrm{b}}$ Number of plants positive/total number sampled.

${ }^{\mathrm{c}}$ No plants collected.

Table 3. Transmission of lettuce mosaic potyvirus (LMV) from gazania to lettuce and from lettuce and Nicotinana benthamiana to gazania

\begin{tabular}{|c|c|c|c|}
\hline Inoculation method & Source species & Inoculated species & No. infected/no. inoculateda \\
\hline \multirow[t]{5}{*}{ Sap } & Gazania & Lettuce & $21 / 60^{b}$ \\
\hline & & C. quinoa & $41 / 60$ \\
\hline & & N. benthamiana & $34 / 60$ \\
\hline & Lettuce & Gazania $^{\mathrm{c}}$ & $54 / 57$ \\
\hline & N. benthamiana & Gazania $^{\mathrm{c}}$ & $15 / 15$ \\
\hline \multirow[t]{4}{*}{ Aphids ${ }^{d}$} & Gazania & Lettuce & $17 / 54$ \\
\hline & & N. benthamiana & $5 / 12$ \\
\hline & Lettuce & Gazania & $17 / 25$ \\
\hline & & N. benthamiana & $11 / 25$ \\
\hline
\end{tabular}

a Results represent number of plants that tested positive for LMV infection based on indirect enzyme-linked immunosorbent assay/total number of plants inoculated.

${ }^{\mathrm{b}}$ Numbers represent totals for three separate experiments.

${ }^{c}$ Two different types of gazanias were inoculated: one type with glabrous, lobed leaves and white flowers, and the other with non-glabrous, smooth leaves and yellow flowers.

${ }^{\mathrm{d}}$ Myzus persicae was used in all aphid inoculations. 


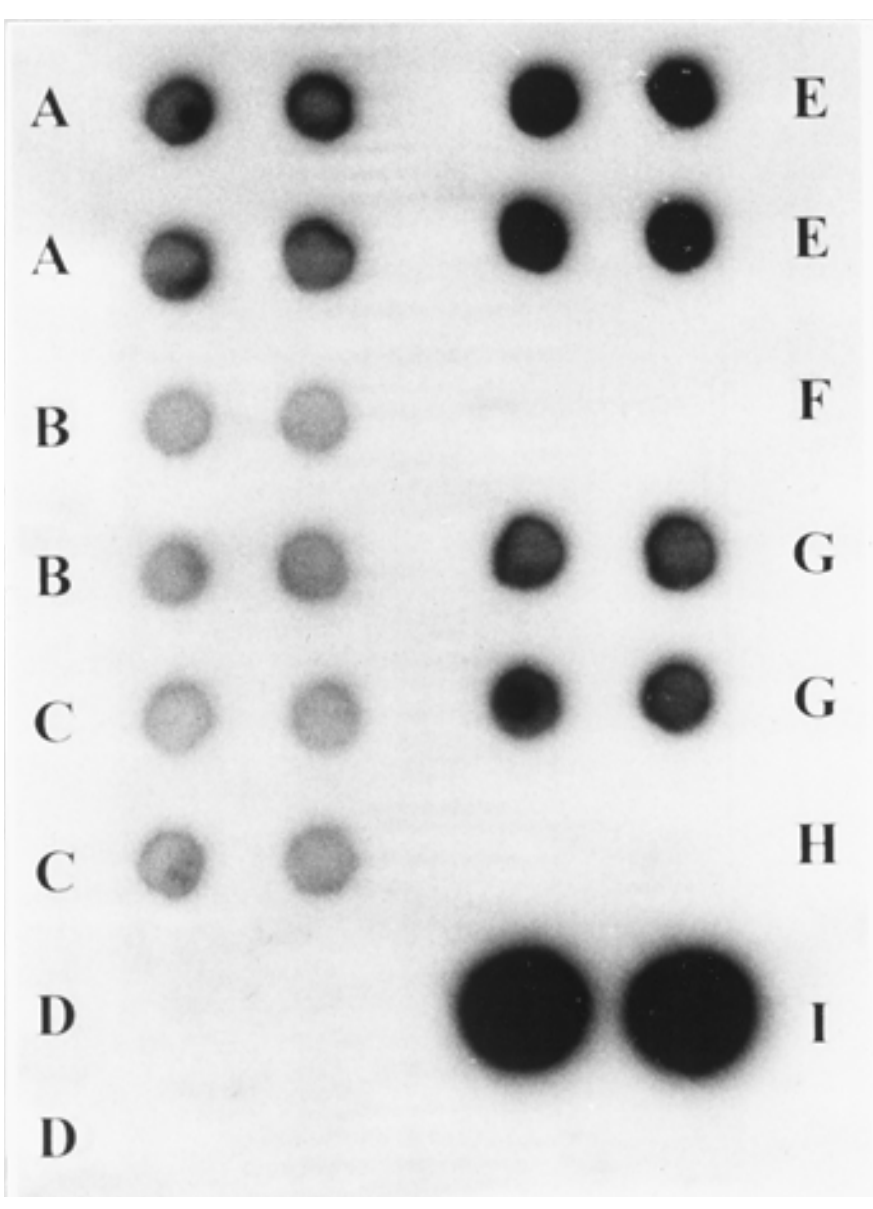

Fig. 3. Dot blots of extracts prepared from Gazania spp., lettuce, and Nicotiana benthamiana plants and hybridized with a lettuce mosaic potyvirus (LMV) coat protein (CP) gene probe. (A), (B), and (C), LMV-infected gazania samples having high, medium, and low virus titers, respectively (as previously determined by indirect enzyme-linked immunosorbent assay). (D) Uninfected gazania. (E) LMV-infected Nicotiana benthamiana. (F) Uninfected $N$. benthamiana. (G) LMV-infected lettuce. (H) Uninfected lettuce. (I) LMV CP plasmid DNA control.

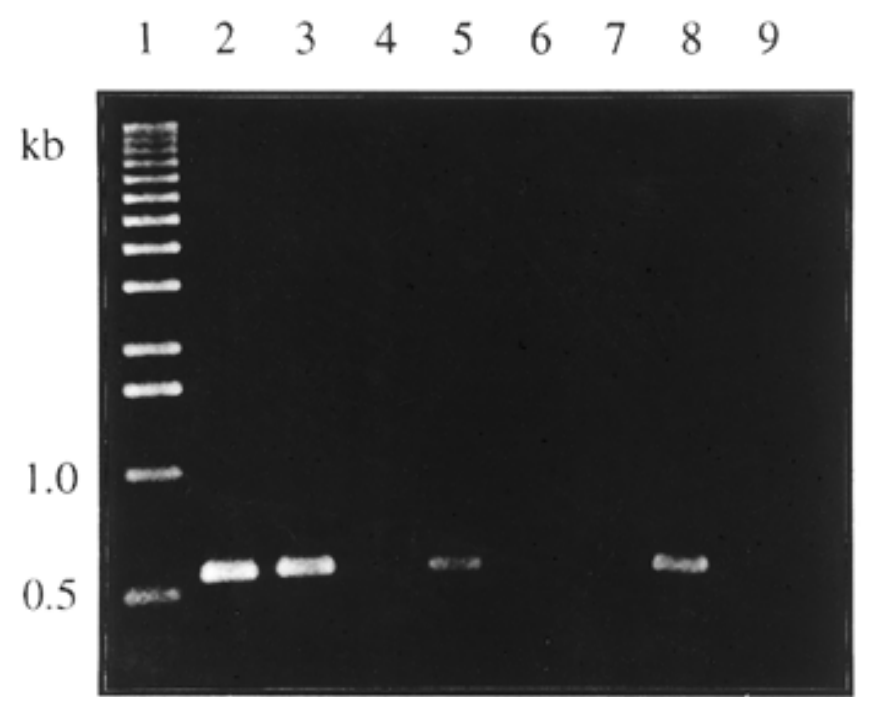

Fig. 4. Detection of lettuce mosaic potyvirus (LMV) by reverse transcription-polymerase chain reaction amplification. A primer pair designed based on the LMV coat protein (CP) gene sequence was used to direct the amplification of a 600-bp LMV CP fragment from total nucleic acid extracts. Lanes: 1, 1 kilobase ladder (BRL); 2, LMV-infected lettuce; 3, LMV-infected Nicotiana benthamiana; 4, uninfected $N$. benthamiana; 5, LMV-infected gazania (1:10 dilution); 6, LMV-infected gazania (1:1 dilution); 7, uninfected gazania (1:10 dilution); 8, LMV CP plasmid DNA control; 9, water (negative) control.
( $46 \%$ infection) and three of four nurseries in 1994 (42\% infection), and mixed infections of LMV and CMV were detected in 1993 and 1994 (Table 2). TuMV infection was not detected in gazanias collected from commercial nurseries.

Transmission of LMV from Gazania spp. Initial attempts to sap-transmit LMV from gazania to other plant species were unsuccessful or resulted in very low levels of transmission. The addition of a strong reducing agent to the grinding buffer followed by centrifugation of the sap resulted in an increased frequency of sap transmission, presumably due to the inactivation and/or removal of inhibitors present in gazania leaf tissue. LMV was consistently sap-transmitted from infected gazanias to lettuce, $N$. benthamiana, and $C$. quinoa plants (Table 3). Lettuce plants inoculated with sap prepared from LMV-infected gazania developed typical LMV symptoms including mosaic, leaf distortion, and, occasionally, necrotic spots. $N$. benthamiana plants developed symptoms including mottling and leaf distortion, and C. quinoa developed chlorotic lesions and leaf distortion. In some cases, sap-inoculated plants were also infected by CMV. However, CMV-infected plants were readily differentiated from LMV-infected plants based on symptoms (i.e., mild mosaic in lettuce, large chlorotic spots in $C$. quinoa, and strong epinasty, chlorosis, and wilting in $N$. benthamiana) and I-ELISA. LMV was also efficiently sap-transmitted from lettuce and $N$. benthamiana to gazania (Table 3 ). Some of the LMV-infected gazanias developed symptoms similar to those observed in field samples, including yellow mosaic, chlorotic spots, and leaf distortion. However, in most cases, LMV-infected gazanias did not show obvious symptoms. Gazanias that were coinoculated with LMV and CMV by sap inoculation became infected with both viruses, but most infected plants remained symptomless, although a few plants developed mosaic and leaf distortion.

In order to prevent accidental transmission of CMV in the aphid transmission experiments, gazanias that had tested positive for LMV and negative for CMV were used as the source of LMV. In these experiments, LMV was aphid transmitted from infected gazanias to lettuce and $N$. benthamiana, and from lettuce to gazania (Table 3). Aphid-inoculated plants developed symptoms similar to those in plants infected with LMV by sap transmission.

Detection of LMV RNA in Gazania spp. LMV RNA was detected in gazania leaf tissue by dot blot hybridization with an LMV CP probe. Under high stringency conditions, the probe hybridized to dot blots of LMV-infected gazania, $N$. benthamiana, and lettuce plants, but not to dot blots of uninfected plants (Fig. 3). Dot blot hybridization results were consistent with those of I-ELISA for all samples tested, 
i.e., gazanias indicated to be uninfected by LMV based on I-ELISA tested negative for LMV RNA by dot blot hybridization, whereas gazanias indicated to be infected by LMV based on I-ELISA tested positive for LMV RNA by dot blot hybridization. Most importantly, dot blot hybridization results confirmed the presence of LMV RNA in gazanias that were slightly above the positive/negative threshold in IELISAs.

An approximately 600-bp DNA fragment was amplified from LMV-infected gazania (I-ELISA positive) by RT-PCR with an LMV CP primer pair (Fig. 4). Inhibitors of the RT-PCR reaction were present in undiluted nucleic acid extracts prepared from gazania leaves, and it was necessary to dilute the nucleic acid extract in order to amplify the 600-bp fragment (Fig. 4). No DNA fragment was amplified from uninfected (I-ELISA negative) plants. The DNA fragment amplified from LMVinfected gazania was cloned, and its nucleotide sequence was determined. DNA sequence comparisons revealed that the sequence of this DNA fragment was $99 \%$ identical to the $\mathrm{CP}$ gene sequence of a LMV isolate (LMV-Sp) (14) recovered from lettuce from the Salinas Valley (Fig. $5)$.

Field transmission of LMV from Gazania spp. To determine whether LMV could be transmitted from gazania to lettuce in a field situation, microplots of lettuce transplants were established among plantings of gazanias known to contain LMV-infected plants. In 1994, lettuce transplants were also established among a planting of gazania that did not have LMVinfected plants ("control"). Although some of the lettuce transplants were lost at all locations due to damage by slugs, some transplants from all four locations in both years of the study became infected by LMV (Table 4), whereas none of the lettuce transplants growing among the gazanias at the "control" location became infected by LMV (Table 4).

\section{DISCUSSION}

Lettuce mosaic no longer occurs at epidemic levels in the Salinas Valley, because of an ongoing, integrated LMV management program. However, because of the potentially devastating consequences of this disease, recent localized LMV outbreaks raised concerns about the possible reemergence of LMV in this major lettucegrowing area (10). In a previous study, it was determined that the introduction or emergence of serologically or genetically distinct LMV strains was not responsible for these outbreaks (14). Therefore, the role of alternate hosts, particularly ornamental plants, was investigated.

A significant finding of this study was the identification of Gazania spp. as a new and widespread ornamental host of LMV in the Salinas Valley. Gazania spp. are members of the Asteraceae (Compositae) family, which includes lettuce and numerous other species that are susceptible to LMV. Gazanias are prostrate, droughttolerant perennials that produce large numbers of attractive, bright-colored, daisylike flowers. These properties make gazania a popular groundcover plant for landscape plantings in the Salinas Valley and many other regions of California.

The frequent occurrence of viruslike symptoms in gazanias in the Salinas Valley led to the identification of gazania as an LMV host, but the presence of viruslike

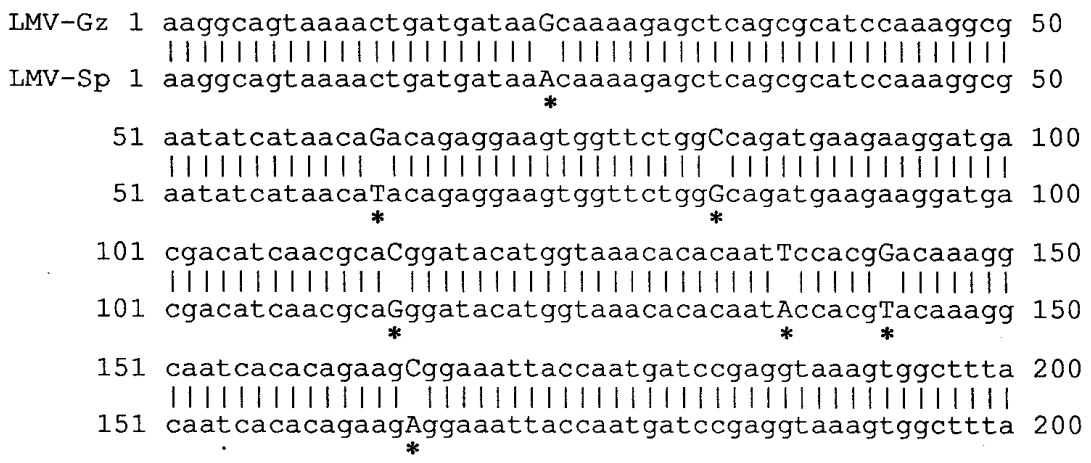

201 aacctgatcatttgctggagtacgaaccaaaccagagagacatatcgaa 250

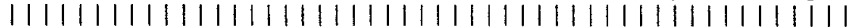

201 aaccttgatcatttgctggagtacgaaccaaaccagagagacatatcgaa 250

251 cacacgtgcaacccagaaacagtacgagtcatggtacgacggggttaaga 300 |||||||||||||||||||||||||||||||||||||||||||||||||

251 cacacgtgcaacccagaaacagtacgagtcatggtacgacggggttaaga 300

301 atgactacgatgtggatgatagtggcatgcaattaattctgaacggattg 350

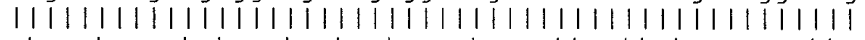

301 atgactacgatgtggatgatagtggcatgcaattaattctgaacggattg 350

351 aaggtttggtgtatagaaaacgagacatccccgaatataatggaacatg 400

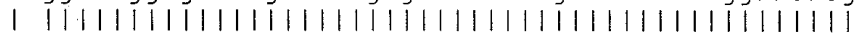

351 atggtttggtgtatagaaaacgagacatccccgaatataaatggaacatg 400

401 gctgatgatggatggtgaagaacaggtagaatatgctctaaaacccatca 450

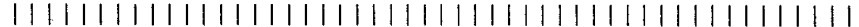

401 gctgatgatggatggtgaagaacaggtagaatatgctctaaaacccatca 450

451 tcgaacacgcgaaacccacgtttcgccagataatggcccatttcagtgac 500

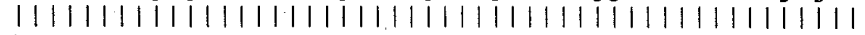
451 tcgaacacgcgaaacccacgtt cgccagataatggcccatt cagtgac 500

501 gcagccgaggcgtacattgagatgagaaacaagaagaaaccgtatatgce 550

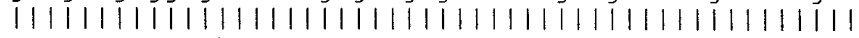

501 gcagccgaggcgtacattgagatgagaaacaagaagaaaccgtatatgcc 550

551 acgatacggacggctacgagg 571 11111111111111111111

551 acgatacggacggctacgagg 571

Fig. 5. Nucleotide sequence alignment of a fragment of the lettuce mosaic potyvirus (LMV) coat protein (CP) gene (representing amino acids 10 to 198) amplified from gazania (LMV-Gz) by reverse transcription-polymerase chain reaction and the CP gene sequence of an LMV isolate from lettuce from the same area of the Salinas Valley (LMV-Sp). Nucleotides that are different between the two sequences are indicated with asterisks (beneath the nucleotides), and are shown in capital letters.

Table 4. Lettuce mosaic potyvirus (LMV) infection of lettuce plants transplanted among LMVinfected gazanias

\begin{tabular}{lcc}
\hline Year of experiment & Location & No. infected/no. sampled \\
\hline 1993 & Firestone Plant & $12 / 27$ \\
& Spreckles Rd. I & $5 / 25$ \\
& Spreckles Rd. II & $9 / 27$ \\
1994 & Hwy. 68 & $3 / 14$ \\
& Firestone Plant & $6 / 25$ \\
& Spreckles Rd. I & $12 / 25$ \\
& Spreckles Rd. II & $12 / 36$ \\
& Hwy. 68 & $17 / 22$ \\
& UCCE & $0 / 25^{\mathrm{b}}$
\end{tabular}

a Results represent number of plants that tested positive for LMV infection based on indirect enzyme-linked immunosorbent assay (I-ELISA)/total number of plants tested.

b At this location gazanias were not infected with LMV based on I-ELISA results from randomly sampled gazania plants. 
symptoms is not a reliable indicator of LMV infection. Some LMV-infected gazanias collected in the Salinas Valley as well as gazanias infected with LMV in sap transmission experiments did not show symptoms. These results indicate that, under certain conditions, gazanias can be a symptomless host for LMV. In contrast, some gazanias with striking, viruslike symptoms were not infected by LMV and these symptoms were associated with infection by other viruses, particularly CMV. Examination of leaf-dip preparations from symptomatic gazanias also revealed a variety of viruslike particles, suggesting infection by additional viruses. Thus, gazanias can be infected by a number of viruses, and symptoms are not sufficient for viral identification.

The expression and/or development of symptoms in virus-infected gazania may also be dependent on other factors such as host genotype and environmental factors. Gazania spp. appear to be a genetically diverse group of plants based upon the wide range of leaf morphologies and flower colors observed in commercially available plants. Viruslike symptoms appeared to be more prominent in certain types of gazanias, suggesting the influence of host genotype on symptom expression. The fact that gazanias infected with LMV, CMV, or LMV and CMV in the sap and aphid transmission experiments frequently failed to develop symptoms suggests that environmental conditions may also influence symptom expression.

Because symptoms were not a reliable indicator of LMV infection, several lines of evidence in addition to I-ELISA were used to prove that gazanias were infected with LMV. First, LMV was sap transmitted from infected gazania to lettuce, $C$. quinoa, and $N$. benthamiana; these sap-inoculated plants developed characteristic symptoms of LMV infection, and were positive for LMV infection based upon I-ELISA results. Second, dot blot hybridization established the presence of LMV RNA in infected gazanias, and dot blot results were in agreement with results of I-ELISAs, including some samples having I-ELISA readings that were slightly above the positive/negative threshold. These "low" ELISA-positive readings probably reflect a low LMV titer in field-collected gazanias, possibly due to environmental conditions, gazania genotype, and/or the physiological state of the plant. Finally, definitive evidence of LMV infection in gazania was provided by RT-PCR amplification, cloning, and sequencing of a portion of the $\mathrm{CP}$ gene of an LMV isolate from gazania. The sequence of the CP fragment amplified from infected gazania was $99 \%$ identical to the sequence of an LMV CP fragment am- plified from LMV-infected lettuce (LMV$\mathrm{Sp}$ ) in the Salinas Valley, which is well within the range of $\mathrm{CP}$ sequence similarities found among LMV isolates in the Salinas Valley (95 to 99\%) (14). Taken together, these results establish that gazania is a host of LMV.

A number of findings also support the hypothesis that LMV-infected gazanias may be an inoculum source for recent LMV outbreaks in the Salinas Valley. LMV-infected gazanias were widespread in the Salinas Valley and were found near LMV hot spots. The LMV isolate from gazania that was partially characterized at the molecular level was nearly identical to an LMV isolate recovered from an infected lettuce plant collected from a hot-spot area (based on sequence identity of the CP fragment). The ability of aphids to transmit LMV from gazania to lettuce established a potential mode of transmission from gazania to lettuce, and evidence for transmission of LMV from gazania to lettuce in the field came from experiments in which lettuce plants grown among LMV-infected gazanias became infected with LMV within 4 weeks of transplanting. Although it was not experimentally demonstrated, it is likely that LMV was transmitted from gazania to lettuce by aphids present in the gazania plantings. Together, these results suggest that gazanias can be an inoculum source for LMV infection of lettuce under field conditions.

Nursery surveys established that LMVinfected gazanias were being sold at local nurseries, which indicated that gazanias were not becoming infected by LMV after being planted in the Salinas Valley. Most of these nurseries purchase gazanias from wholesale sources located outside the Salinas Valley, suggesting that at least some of the LMV infection of these plants occurred at the locations where they were propagated. The primary inoculum source for LMV infection of gazanias may be contaminated seed, and the low incidence of LMV-infected gazanias found at nurseries in 1994 could have been due to the use of a seed lot having a low incidence of LMV contamination. However, seed transmission of LMV in Gazania spp. has yet to be demonstrated, and additional experiments are necessary to determine whether LMV is seed-borne in gazania.

The results of this study provide strong circumstantial evidence that gazanias are an inoculum source for the recent LMV outbreaks in the Salinas Valley, although other ornamental and weed hosts may also serve as inoculum sources. To minimize the role of gazanias as an LMV inoculum source, it is recommended that nurseries produce LMV-free gazanias, possibly through the use of gazania seed and/or plants indexed free of LMV infection.

\section{ACKNOWLEDGMENTS}

We wish to thank the California Iceberg Lettuce Research Advisory Board for financial support, Bryce W. Falk and Tongyan Tian for help with the aphid inoculations, Maria Vidauri for help with the field trials, and R. M. Davis and R. W. Michelmore for critical review of the manuscript. The first author was supported by a fellowship from the National Research Council of Brazil (CNPq).

\section{LITERATURE CITED}

1. Ausubel, F. M., Brent, R., Kingston, R. E., Moore, D. D., Seidman, J. D., Smith, J. A., and Struhl, K., eds. 1991. Current Protocols in Molecular Biology. John Wiley and Sons, New York.

2. Clark, M. F., Lister, R. M., and Bar-Joseph, M. 1986. ELISA techniques. Methods Enzymol. 118:742-766.

3. Grogan, R. G. 1980. Control of lettuce mosaic with virus-free seed. Plant Dis. 64:446-449.

4. Grogan, R. G., Welch, J. E., and Bardin, R. 1952. Common lettuce mosaic and its control by the use of mosaic-free seed. Phytopathology 42:573-578.

5. Horvath, J. 1991. Unknown Compositae (Asteraceae) hosts of lettuce mosaic potyvirus. Acta Phytopathol. Entomol. Hung. 26: 347-351.

6. Langeveld, S. A., Dore, J. M., Memelink, J., Derks, A. F. L. M., van der Vlugt, C. I. M., Asjes, C. J., and Bol, J. F. 1991. Identification of potyviruses using the polymerase chain reaction with degenerate primers. J. Gen. Virol. 72:1531-1541.

7. Lisa, V., Dellavalle, G., and Ramasso, E. 1995. Il virus del mosaico della latuga su lisianthus. Inf. Fitopatol. 3:58-59.

8. McLean, D. L., and Kinsey, M. G. 1962. Three variants of lettuce mosaic virus and methods used for differentiation. Phytopathology 52:403-406.

9. Opgenorth, D. C., White, J. B., Oliver, B., and Greathead, A. S. 1991. Freeway daisy (Osteospermum fruticosum) as a host for lettuce mosaic virus. Plant Dis. 75:751.

10. Pryor, A. 1987. Mosaic miseries. Calif. Farmer 267:32-33.

11. Sambrook, J., Fritsch, E. F., and Maniatis, T. A. 1989. Molecular Cloning: A Laboratory Manual. 2nd ed. Cold Spring Harbor Laboratory, Cold Spring Harbor, NY.

12. Sanger, F., Nicklein, S., and Coulson, A. R 1977. DNA sequencing with chain-terminating inhibitors. Proc. Natl. Acad. Sci. USA 74: 5463-5467.

13. Tomlinson, J. A. 1970. Lettuce mosaic virus. No. 9 in: Descriptions of Plant Viruses. Commonw. Mycol. Inst. Assoc. Appl. Biol., Kew, England.

14. Zerbini, F. M., Koike, S. T., and Gilbertson, R. L. 1995. Biological and molecular characterization of lettuce mosaic potyvirus isolates from the Salinas Valley of California. Phytopathology 85:746-752.

15. Zerbini, F. M., Jr., Koike, S. T., and Gilbertson, R. L. 1993. Gazania spp.: An alternate host of lettuce mosaic potyvirus (LMV) in the Salinas Valley. Phytopathology $83: 1420$.

16. Zink, F. W., Duffus, J. E., and Kimble, K. A. 1973. Relationship of a non-lethal reaction to a virulent isolate of lettuce mosaic virus and turnip mosaic susceptibility in lettuce. J. Am. Soc. Hortic. Sci. 98:41-45. 